\title{
Neuroactive steroids influence peripheral myelination: a promising opportunity for preventing or treating age-dependent dysfunctions of peripheral nerves
}

\author{
R.C. Melcangi ${ }^{\text {a } *}$, I. Azcoitia ${ }^{b}$, M. Ballabio ${ }^{a}$, I. Cavarretta ${ }^{a}$, L.C. Gonzalez ${ }^{\text {a }}$, \\ E. Leonelli ${ }^{\text {a }}$, V. Magnaghi ${ }^{\text {a }}$, S. Veiga ${ }^{\text {a,c }}$, L.M. Garcia-Segura ${ }^{c}$ \\ a Department of Endocrinology, Center of Excellence on Neurodegenerative Diseases, \\ University of Milan, Via G. Balzaretti 9, 20133 Milan, Italy \\ ${ }^{\mathrm{b}}$ Departamento de Biología Celular, Facultad de Biología, Universidad Complutense, E-28040 Madrid, Spain \\ ${ }^{\mathrm{c}}$ Instituto Cajal, C.S.I.C., 28002 Madrid, Spain
}

Received 30 May 2003; accepted 11 September 2003

\begin{abstract}
The process of aging deeply influences morphological and functional parameters of peripheral nerves. The observations summarized here indicate that the deterioration of myelin occurring in the peripheral nerves during aging may be explained by the fall of the levels of the major peripheral myelin proteins [e.g., glycoprotein Po (Po) and peripheral myelin protein 22 (PMP22)]. Neuroactive steroids, such as progesterone (PROG), dihydroprogesterone ( $5 \alpha-\mathrm{DH}$ PROG), and tetrahydroprogesterone ( $3 \alpha, 5 \alpha-\mathrm{TH}$ PROG), are able to stimulate the low expression of these two myelin proteins present in the sciatic nerve of aged male rats. Since Po and PMP22 play an important physiological role in the maintenance of the multilamellar structure of PNS myelin, we have evaluated the effect of PROG and its neuroactive derivatives, $5 \alpha$-DH PROG and 3 $\alpha, 5 \alpha$-TH PROG, on the morphological alterations of myelinated fibers in the sciatic nerve of 22-24-month-old male rats. Data obtained clearly indicate that neuroactive steroids are able to reduce aging-associated morphological abnormalities of myelin and aging-associated myelin fiber loss in the sciatic nerve.
\end{abstract}

(C) 2003 Elsevier Ltd. All rights reserved.

\section{Contents}

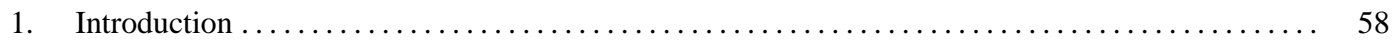

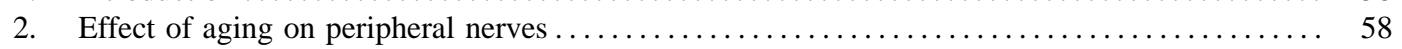

3. Glycoprotein Po and peripheral myelin protein 22: two important myelin proteins of the

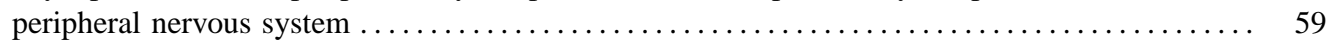

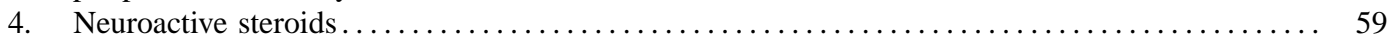

5. Aging affects myelin protein levels and neuroactive steroid formation . . . . . . . . . . ... 60

6. Effects of neuroactive steroids on peripheral myelin proteins $\ldots \ldots \ldots \ldots \ldots \ldots \ldots \ldots \ldots \ldots$

7. Effects of neuroactive steroids on morphology of peripheral myelin $\ldots \ldots \ldots \ldots \ldots \ldots \ldots \ldots .62$

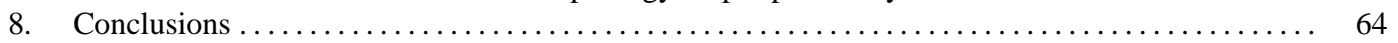

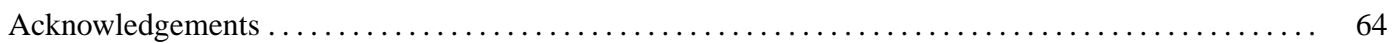

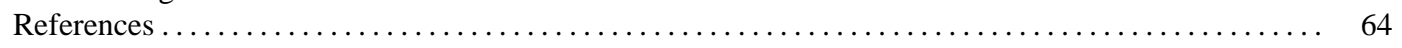

Abbreviations: $3 \alpha$-diol, $5 \alpha$-androstan-3 $\alpha, 17 \beta$-diol; $3 \alpha$-HSD, $3 \alpha$-hydroxysteroid-dehydrogenase; $3 \alpha, 5 \alpha$-TH PROG, tetrahydroprogesterone; $5 \alpha-\mathrm{DH}$ PROG, dihydroprogesterone; $5 \alpha-\mathrm{R}, 5 \alpha$-reductase; AR, androgen receptor; CIDP, chronic inflammatory demyelinating polyneuropathy; CMT1A, Charcot-Marie-Tooth type $1 \mathrm{~A}$; CMT1B, Charcot-Marie-Tooth type $1 \mathrm{~B}$; CNS, central nervous system; DSS, Déjérine-Sottas syndrome; DHT, dihydrotestosterone; HNNP, hereditary neurophaty with liability to pressure palsies; MBP, myelin basic protein; NGF, nerve growth factor; PMP22, peripheral myelin protein 22; PNS, peripheral nervous system; Po, glycoprotein Po; PR, progesterone receptor; PRE, progesterone-responsive elements; PROG, progesterone; T, testosterone

* Corresponding author. Tel.: +39-02-50318238; fax: +39-02-50318204.

E-mail address: roberto.melcangi@unimi.it (R.C. Melcangi). 


\section{Introduction}

The search for molecules that are able to promote healthy aging and reverse age-dependent alterations of the nervous system represents an important goal for biomedical research. The aim of the present review will be to discuss in particular the changes occurring in the peripheral nervous system (PNS), with a particular focus on myelin of peripheral nerves and on its protein components. Recent results obtained in our and other laboratories indicating that neuroactive steroids stimulate the expression of myelin proteins of PNS and are able to counteract the effects of the process of aging on the myelin compartment of peripheral nerves will be summarized.

\section{Effect of aging on peripheral nerves}

The aging process induces important morphological and functional changes in peripheral nerves. It is well known that large myelinated fibers undergo atrophy, while myelin sheaths increase in thickness and show various irregularities (Thomas et al., 1980; Dyck et al., 1981; Grover-Johnson and Spencer, 1981; Adinolfi et al., 1991; Johansson et al., 1996). In the sciatic nerve of normal old cats, anomalies are characterized by the retraction of the lateral loops adjacent to the nodes of Ranvier, by vacuolation, by fragmentation or by the appearance of "bubbles". At the ultrastructural level, different stages of demyelination are evident. In particular, it is possible to observe an accumulation of mitochondria, lipid-like droplets, as well as heterogeneous granular and vacuolar materials in the outer cytoplasmic compartment of Schwann cells, and in the distended portion of the inner adaxonal rim (Adinolfi et al., 1991). Disruption of one or more segments of the myelin sheaths also occurs; this disruption is produced by interlamellar splitting and ballooning along the major dense line and the intraperiod lines (Adinolfi et al., 1991). Peripheral nerves of rats show similar morphological changes (e.g., myelin ballooning, splitting, infolding, reduplication and remyelination) (Knox et al., 1989; Verdù et al., 2000). We have recently observed that in sciatic nerve of aged rat the most frequent of these abnormalities was the presence of myelin infoldings into the axoplasm. Myelin infoldings were observed in $7 \%$ of myelinated fibers in the nerves of young rats. The proportion of fibers with myelin infoldings was significantly increased in aged animals $(6.98 \pm 0.98 \%$ versus $34.55 \pm 2.76 \%$ of fibers with myelin infoldings in young and old rats, respectively; $P<$ $0.05)$. In contrast, myelin outfoldings and abnormalities in myelin compaction affected less than $2 \%$ of the myelinated fibers and did not significantly increase in aged animals (Azcoitia et al., 2003).

Other morphological changes imply the relations between nodal spacing and fiber diameters, which become increasingly variable due to nodal widening, paranodal and/or segmental demyelination accompanied by remyelination (Knox et al., 1989). Wallerian-type degeneration followed by axonal regeneration and myelination also occur (Lascelles and Thomas, 1966; Thomas et al., 1980; Grover-Johnson and Spencer, 1981; Braund et al., 1982a,b; Berthold et al., 1983; Verdù et al., 2000).

Morphological changes due to aging are also evident in unmyelinated nerve fibers. For instance, a morphometric study performed on unmyelinated fibers present in human sural nerve indicated that the percentage of subunits containing unmyelinated axons and the mean number of axons in single axon-containing Schwann cells subunits are significantly decreased (Kanda et al., 1991). On the contrary, other parameters like the density of Schwann cells subunits with and/or without axons, the single protrusion of Schwann cells, the collagen pockets, and the mean number of Schwann cells profiles per axon are significantly increased (Kanda et al., 1991). A reduction in the number of density of myelinated fibers has been reported with aging in peripheral nerves of several animal species (Verdù et al., 2000). In agreement, we have recently observed that the density of myelinated fibers is clearly reduced in the sciatic nerve of aged rats: the total number of myelinated fibers was significantly decreased in old animals $(10,512 \pm 751$ versus $7328 \pm 336$ fibers per nerve in young and aged rats, respectively; $P<0.05$ ) (Azcoitia et al., 2003). The effect of aging is particularly evident in myelinated fibers of small caliber. Thus, more than $60 \%$ of the myelinated fibers with a diameter under $5 \mu \mathrm{m}$ are lost in aged animals $(2459 \pm 182$ versus $900 \pm 161$ fibers per nerve in young and aged rats, respectively; $P<0.05$ ). The total number of unmyelinated axons is also significantly reduced by aging $(16,194 \pm 1742$ versus $11,130 \pm 823$ axons per nerve in young and aged rats, respectively; $P<0.05$ ) (Azcoitia et al., 2003).

Alterations in the size and shape of myelinated fibers also occur with aging. The majority (>80\%) of myelinated fibers in the sciatic nerve of young rats show a circular or ovoidal profile in cross-sections. However, lobulated, triangular and crescent-shaped profiles are also observed (Azcoitia et al., 2003). The irregular shapes are increased with aging. Thus, less than $50 \%$ of the myelinated fibers in old animals had a circular or ovoidal profile $(17 \pm 3 \%$ versus $55 \pm 3 \%$ of fibers with irregular shapes in young and old rats, respectively; $P<0.05)$ (Azcoitia et al., 2003). It is interesting to note that similar changes have been related to a decrease of neurofilament mRNA levels; as shown by Parhad et al. (1995), such levels decreased at the levels of rat PNS of about $60 \%$ at 23 months of age.

Moreover, the aging process also affects functional parameters. For instance, electrophysiologic studies have shown that nerve conduction velocity is lower in aged subjects than in young ones (Verdù et al., 2000). However, the rate of decline of nerve conduction velocity depends on the type of fiber (afferent versus efferent), the nerve and the animal species (Wagman and Lesse, 1952; Norris et al., 1953; Wayner and Emmers, 1958; Burke et al., 1974; Sato et al., 1985; Swallow and Griffiths, 1977; Rivner et al., 2001). For 
instance, in aged rats, there is no change in the conduction velocity of the phrenic nerve until 28 months of age (Smith and Rosenheimer, 1984), but a decrease in spinal nerve is evident (Retzlaff and Fontaine, 1965; Koella, 1979). In female mice, the amplitude of muscle action potentials recorded from the plantar and tail muscles decreases linearly with age from 2 to 24 months. Furthermore, the latency of the onset of the muscle action potential declines from 2 to 6 months, remains unchanged between 6 and 12 months, and is increased in older mice (Verdù et al., 1996). On the contrary, the conduction velocity of unmyelinated fibers seems to be unaffected by the aging process (Sato et al., 1985).

\section{Glycoprotein Po and peripheral myelin protein 22: two important myelin proteins of the peripheral nervous system}

Proteins present in the myelin of PNS include glycoprotein Po (Po), peripheral myelin protein 22 (PMP22), myelin basic protein (MBP), myelin-associated glycoprotein and connexin 32. Among these, Po and PMP22 seem to exert an important role for the maintenance of the multilamellar structure of PNS myelin. In particular, Po, which accounts for over $50 \%$ of PNS myelin protein, is synthesized by Schwann cells and then predominantly confined to the compact portion of the mature myelin. Po is a simple integral membrane glycoprotein, with single transmembrane, extracellular and cytoplasmic domains, and is a member of the immunoglobulin gene superfamily (Lemke and Axel, 1985; Sakamoto et al., 1987; Eichberg, 2002). Po is believed to play a major role in the compaction of normal myelin serving as a bifunctional structural element linking adjacent lamellae, and thereby stabilizing the assembly of the myelin (Lemke, 1986; D’Urso et al., 1990; Snipes and Suter, 1995).

The importance of Po for stabilizing compact myelin is illustrated by the severe phenotype of Po-negative mice generated by homologous recombination. They show abnormal motor coordination, tremors, axon degeneration, and a severe hypomyelination with decompaction of myelin in very young ages followed by degeneration of myelin and formation of onion bulbs (Giese et al., 1992; Martini et al., 1995; Zielasek et al., 1996). With progressing age, these abnormalities become more pronounced (see Section 5). These pathological alterations resemble those seen in some dominantly inherited human peripheral neuropathies (e.g., Charcot-Marie-Tooth type 1B, CMT1B, and Déjérine-Sottas syndrome, DSS).

PMP22, which represents 2-5\% of total peripheral myelin proteins, like Po, is synthesized by Schwann cells and then confined in the compact myelin (Welcher et al., 1991). However, unlike Po, which is nerve-specific, PMP22 is expressed also in other tissues, including lung, gut, and heart (Welcher et al., 1991; Quarles, 1997; Bronstein, 2000). Several alterations of the PMP22 gene have been associated with a set of hereditary peripheral neuropathies in humans
(Charcot-Marie-Tooth type 1A, CMT1A; DSS, and hereditary neurophaty with liability to pressure palsies, HNNP) and with the Trembler and Trembler J alleles in mice (Suter and Snipes, 1995; Naef and Suter, 1998).

The fact that PMP22 contains the carbohydrate group HNK1 has suggested that it may have an adhesive function in myelin (Bronstein, 2000). In fact, it has been demonstrated that PMP22 and Po may form complexes in the myelin membranes. The interactions between these two proteins probably participate in holding adjacent Schwann cell membranes together and in stabilizing myelin compaction (D'Urso et al., 1999).

\section{Neuroactive steroids}

In the last decade, several observations have shown that the capability to synthesize steroid hormones is not only a feature of classical steroidogenic tissues (e.g., gonads and adrenals) but may also occur in the nervous system, forming neurosteroids (Baulieu, 1998; Mellon and Griffin, 2002). Moreover, the nervous system is also able to metabolize neurosteroids into metabolites known as neuroactive steroids. Formation of neurosteroids and neuroactive steroids seems to take place mainly in the glial compartment, and in the PNS is particularly located in Schwann cells (Koenig et al., 1995; Melcangi et al., 1992; Guennoun et al., 1997; Melcangi et al., 1998a; Schumacher et al., 2001). The PNS is able to form neuroactive steroids via the enzymatic complex formed by both $5 \alpha$-reductase $(5 \alpha-\mathrm{R})$

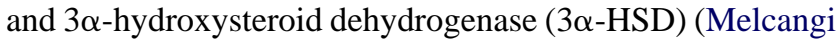
et al., 1992, 1998a, 1999b, 2001a,b). This enzymatic complex is very versatile, since every steroid possessing the delta 4-3keto configuration may be first $5 \alpha$-reduced and subsequently $3 \alpha$-hydroxylated. In particular, testosterone (T) can be converted into dihydrotestosterone (DHT) and then into $5 \alpha$-androstane- $3 \alpha, 17 \beta$-diol ( $3 \alpha$-diol), PROG into $5 \alpha-\mathrm{DH}$ PROG and subsequently into $3 \alpha, 5 \alpha-\mathrm{TH}$ PROG and so on (Melcangi et al., 1999b, 2001b). The $5 \alpha-\mathrm{R}-3 \alpha-\mathrm{HSD}$ enzymatic complex is present both in peripheral nerves (e.g., sciatic nerve) and in Schwann cells in culture. In particular, the $5 \alpha-\mathrm{R}$ activity of Schwann cells is higher than that of oligodendrocytes, their CNS equivalent (Melcangi et al., 1998a), and similar to that found in fetal neurons (Melcangi et al., 1990b, 1993, 1994). In contrast, Schwann cells possess lower $3 \alpha$-HSD activity than oligodendrocytes (Melcangi et al., 1998a).

Schwann cells not only possess the capability to form neuroactive steroids but are also a possible target for some of them. As demonstrated by our own and other laboratories, Schwann cells express mRNA for progesterone receptor (PR) and also the protein itself (Jung-Testas et al., 1996; Magnaghi et al., 1999, 2001). Moreover, they also express non-classical steroid receptors, for instance, the $\mathrm{GABA}_{\mathrm{A}}$ receptor (Melcangi et al., 1999a). Consequently, Schwann cells may respond to neuroactive steroids, such as $3 \alpha, 5 \alpha-\mathrm{TH}$ 
PROG or $3 \alpha$-diol, that are then able to actively interact with this neurotransmitter receptor (Melcangi et al., 1999b, 2001b).

\section{Aging affects myelin protein levels and neuroactive steroid formation}

A clear decrease in the levels of protein Po has been reported in the sciatic nerve of aged rats (Uchida et al., 1986), and in human sural nerve (Koski and Max, 1980). Several observations on the possible effects of aging on peripheral myelin proteins have been made in knockout models (Giese et al., 1992; Martini et al., 1995; Zielasek et al., 1996; Shy et al., 1997; Fruttiger et al., 1995; Nelles et al., 1996; Scherer et al., 1998). For instance, it has been demonstrated that mice lacking one of the two Po alleles by homologous recombination $(\mathrm{Po}+/-)$ have the clinical, electrophysiological, and morphological features of acquired demyelinating neuropathies, such as chronic inflammatory demyelinating polyneuropathy (CIDP). $\mathrm{Po}+/-$ mice are clinically normal until 5 months of age, when they begin to develop a "waddling" gait. The gait disorder progresses for the next 6-8 months and then stabilizes. By 1 year of age, these mice develop severe, asymmetric slowing of motor nerves, with temporal dispersion or conduction block. Morphological analysis reveals severe demyelination of motor fibers, focal regions of demyelination and the presence of inflammatory cells. All these pathological changes are even more pronounced at 20 months (Shy et al., 1997). In humans CIDP is evident between 40 and 60 years of age (McCombe et al., 1987; Mendell, 1993).

Our studies performed by in situ hybridization and/or Northern blot analysis have shown that Po, PMP22 and MBP mRNA levels are all significantly decreased in the sciatic nerves of aged male rats (Melcangi et al., 1998a,b, 1999a). Further observations performed by Western blot analysis have indicated that not only mRNA but also the protein levels of Po and PMP22 proteins are decreased during aging (Fig. 1).

These observations agree with, and provide a possible explanation for, the findings quoted in Section 2 of this review, showing that several morphological and functional aspects of peripheral myelin are profoundly modified during senescence (Spencer and Thomas, 1970; Thomas et al., 1980; Grover-Johnson and Spencer, 1981; Johansson et al., 1996; Downie and Newell, 1961; Morales et al., 1987; Adinolfi et al., 1991; Verdù et al., 1996; Melcangi et al., 2000b; Verdù et al., 2000).

The aging process also affects formation of neuroactive steroids in peripheral nerves. We have observed that aging significantly impairs the formation of $5 \alpha$-reduced metabolites in sciatic nerves of 20-month-old male rats (Melcangi et al., 1990a, 1992). In contrast, aging seems not to affect $3 \alpha$-HSD activity (Melcangi et al., 1990a, 1992).

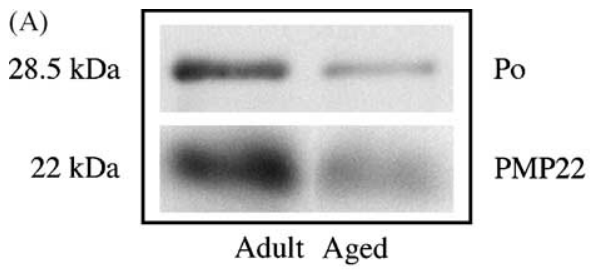

(B)

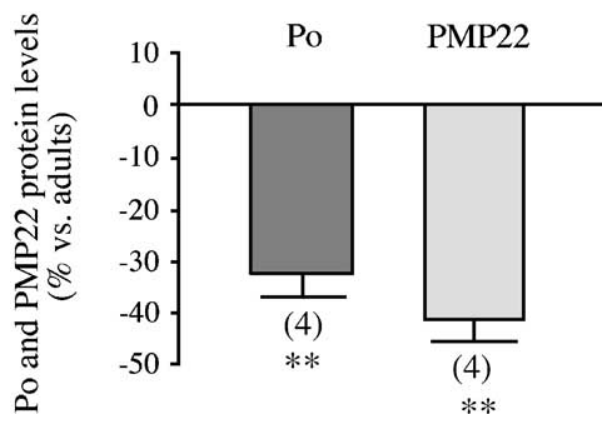

Fig. 1. Effect of aging on the expression of Po and PMP22 in the sciatic nerve of the male rats (22-24 months old). (A) Representative Western blot of one experiment performed. (B) Quantitative data, expressed as percent variation vs. the levels detected in adult (3 months old) male rats (baseline). The columns represent the mean \pm S.E.M. of all determinations performed (numbers in parentheses). ${ }^{* *} P<0.01$ vs. baseline.

\section{Effects of neuroactive steroids on peripheral myelin proteins}

As mentioned in the previous section, aging is associated with a decrease in the synthesis of Po and PMP22 (Melcangi et al., 1998a,b, 1999a, 2000b). Moreover, as mentioned in Section 4, on the basis of the presence of classical and non-classical steroid receptors, it is now well known that PNS and in particular its glial component (i.e., Schwann cells) represent a possible target for the actions of neuroactive steroids. Consequently, we have evaluated whether neuroactive steroids could counteract the drop of Po and PMP22 levels found in the sciatic nerve of aged animals (Melcangi et al., 1998a,b, 1999a, 2000b). To this end, we have treated old male rats (22-24 months old) for 1 month with eight subcutaneous injections of $1 \mathrm{mg}$ of PROG, $5 \alpha-\mathrm{DH}$ PROG or $3 \alpha, 5 \alpha$-TH PROG. Injections were administered every 4 days and mRNA levels of Po and PMP22 were evaluated in the sciatic nerve by Northern blot analysis, $24 \mathrm{~h}$ after the last treatment. Only $5 \alpha-$ DH PROG was able to significantly increase the mRNA levels of Po. In contrast, PROG and $3 \alpha, 5 \alpha-$ TH PROG were unable to significantly modify the gene expression of Po (Melcangi et al., 1998a, 1999a). However, the situation was different when the protein levels of Po were analyzed by Western blot. As shown in Fig. 2, not only $5 \alpha$-DH PROG but also its precursor PROG were able to increase the low protein levels of this myelin protein present in the sciatic nerve of aged rat, suggesting that additional post-transcriptional effects are exerted by these neuroactive steroids on the synthesis of this myelin protein. 


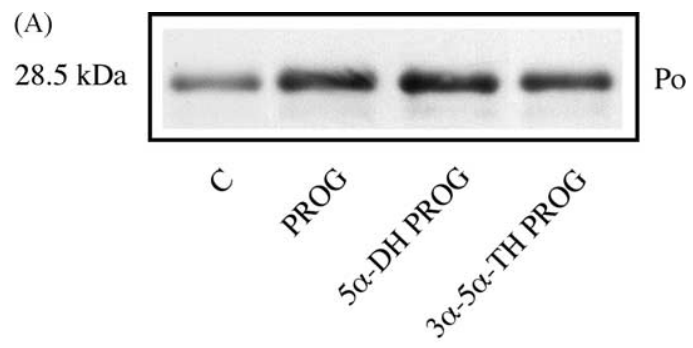

(B)

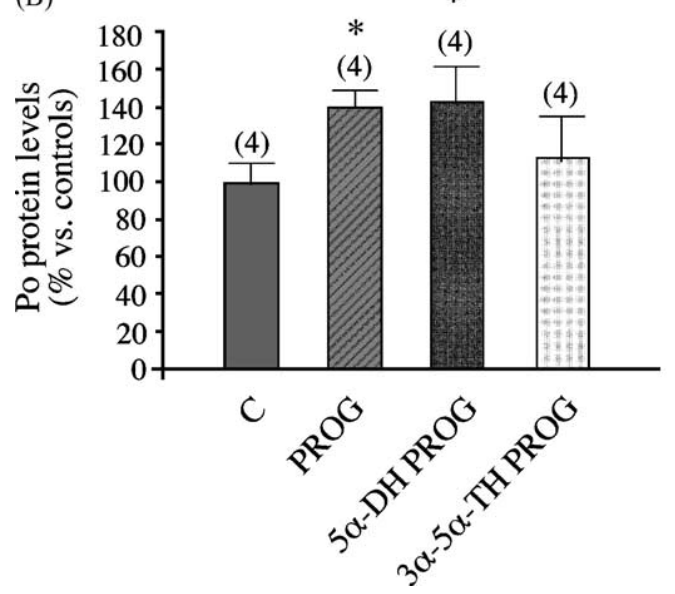

Fig. 2. Effect of in vivo treatment with progesterone (PROG), dihydroprogesterone ( $5 \alpha-\mathrm{DH}$ PROG) or tetrahydroprogesterone $(3 \alpha, 5 \alpha-\mathrm{TH}$ PROG) on Po protein levels in the sciatic nerve of aged male rats (22-24 months old). (A) Representative Western blot of one experiment performed. (B) Quantitative data expressed as percent vs. the levels detected in aged rats treated with vehicle only $(C)$. The columns represent the mean \pm S.E.M. of all determinations performed (numbers in parentheses). ${ }^{* *} P<0.05$ vs. controls.

A very similar situation is evident for PMP22. In fact, in vivo treatments with PROG, $5 \alpha-\mathrm{DH}$ PROG or $3 \alpha, 5 \alpha-\mathrm{TH}$ PROG were unable to increase the low mRNA levels of this myelin protein found in the sciatic nerve of aged male rats (Melcangi et al., 1999a). However, $3 \alpha, 5 \alpha$-TH PROG was able to significantly increase PMP22 protein levels in the sciatic nerve of aged rats (Fig. 3). The effects of PROG and/or its derivatives on Po and PMP22 are also evident in other in vivo and in vitro experimental models. For instance, in the case of Po, in vivo treatments with PROG, $5 \alpha-\mathrm{DH}$ PROG and $3 \alpha, 5 \alpha-$ TH PROG were all effective in increasing Po gene expression in the sciatic nerve of adult male rats; in particular 5 $\alpha$-DH PROG was significantly more effective than the other two steroids (Melcangi et al., 1999a). In the same experimental model, the mRNA levels of PMP22 were significantly increased only by the treatment with $3 \alpha, 5 \alpha-\mathrm{TH}$ PROG (Melcangi et al., 1999a).

Neuroactive steroids, like PROG and its derivatives, may increase gene expression of myelin proteins after peripheral nerve injury. For instance, we have analyzed the possible effects of PROG and of its $5 \alpha$ - and $3 \alpha, 5 \alpha$-reduced metabolites on the gene expression of Po and PMP22 after transection and entubulation techniques to repair the sciatic nerve of adult male rat (Melcangi et al., 2000a). The data obtained

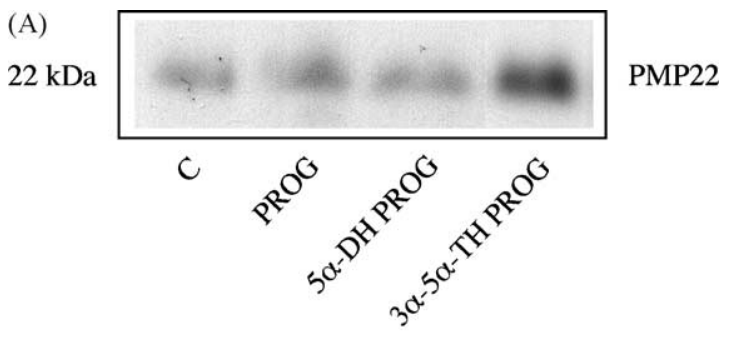

(B)

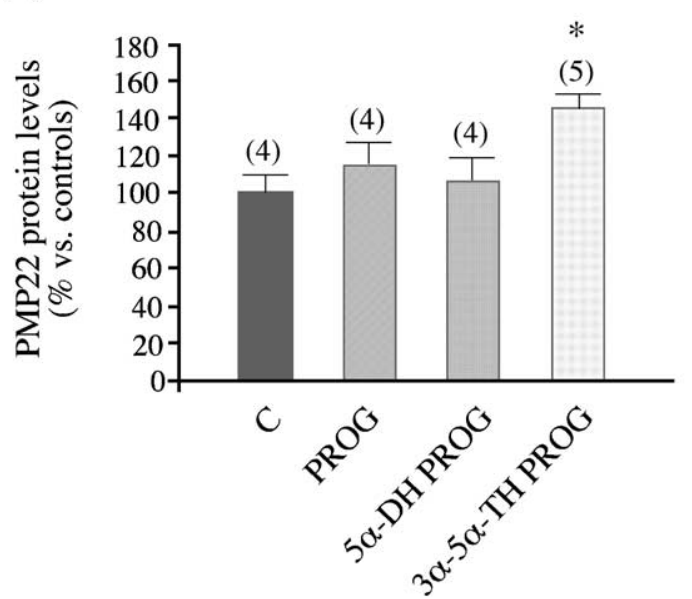

Fig. 3. Effect of in vivo treatment with progesterone (PROG), dihydroprogesterone ( $5 \alpha$-DH PROG) or tetrahydroprogesterone ( $3 \alpha, 5 \alpha-$ TH PROG) on PMP22 protein levels in the sciatic nerve of aged male rats (22-24 months old). (A) Representative Western blot of one experiment performed. (B) Quantitative data expressed as percent vs. the levels detected in aged rats treated with vehicle only (C). The columns represent the mean \pm S.E.M. of all determinations performed (numbers in parentheses). ${ }^{* *} P<0.05$ vs. controls.

indicate that after an experimental period of 2 weeks, both PROG and $5 \alpha$-DH PROG are able to significantly increase the low Po mRNA levels present in the distal portion from the cut of the sciatic nerve (Melcangi et al., 2000a). These findings are in agreement with the results obtained on the basal levels of Po present in the intact sciatic nerve of adult animals (Melcangi et al., 1999a). However, at variance to what was observed in the intact sciatic nerve, $3 \alpha, 5 \alpha$-TH PROG was ineffective in stimulating Po mRNA levels in this experimental model (Melcangi et al., 2000a). Moreover, $3 \alpha, 5 \alpha-\mathrm{TH}$ PROG did not alter PMP22 mRNA levels (Melcangi et al., 2000a), suggesting that the mechanisms by which this neuroactive steroid exerts its effect on the gene expression of these myelin proteins might be altered after peripheral nerve injury. Beneficial effects of PROG and pregnenolone have been also demonstrated by Koenig et al. (1995) who showed that both steroids, when given locally, are able to counteract the decrease of the amounts of myelin membranes induced by a cryolesion in the sciatic nerve of the mouse.

Further experiments performed in our laboratory have indicated that the effects of PROG, $5 \alpha-\mathrm{DH}$ PROG and $3 \alpha, 5 \alpha-$ TH PROG on Po and/or PMP22 gene expression are also evident when cultures of rat Schwann cells are used. 
In agreement with the in vivo results on the intact sciatic nerve of adult male rats, PROG, $5 \alpha$-DH PROG and $3 \alpha, 5 \alpha-$ TH PROG in the case of Po, and $3 \alpha, 5 \alpha-$ TH PROG in the case of PMP22, exert a stimulatory effect on gene expression of these myelin proteins (Melcangi et al., 1998a, 1999a). Moreover, as shown by Désarnaud et al. (1998), PROG also stimulates Po gene expression in a different experimental model (Schwann cells transiently transfected with a reporter construct in which the luciferase expression is controlled by the promoter region of the Po gene). However, at variance with our observations, these authors have found that PROG is also able to stimulate the gene expression of PMP22. In this connection, it is also relevant that in Schwann cells co-cultured with dorsal root ganglia neurons PROG is able to accelerate the time of initiation, and to enhance the rate of myelin synthesis (Chan et al., 1998, 2000).

The data so far mentioned clearly indicate that PROG and/or its derivatives, $5 \alpha$-DH PROG and $3 \alpha, 5 \alpha-$ TH PROG, are able to stimulate the expression of Po and the PMP22. However, they also suggest that the mechanisms involved in these effects are different. Thus, in the case of Po, it is possible that the effects of PROG and 5 $\alpha$-DH PROG might directly involve the PR, which is present both in the sciatic nerve and in cultured Schwann cells (Jung-Testas et al., 1996; Magnaghi et al., 1999, 2001). Moreover, in view of the higher efficacy of $5 \alpha-\mathrm{DH}$ PROG, it is also possible to hypothesize that the conversion of PROG into $5 \alpha-\mathrm{DH}$ PROG, by $5 \alpha-R$ present in the sciatic nerve and in Schwann cells (Melcangi et al., 1992, 1999b, 2001a,b), is a necessary step. Furthermore, since the activity of the $3 \alpha$-HSD is bi-directional (Celotti et al., 1992; Melcangi et al., 1999b, $2001 b$ ), it is possible to assume that the efficacy of $3 \alpha, 5 \alpha-\mathrm{TH}$ PROG, which is not able to directly bind to the PR, may result from a retro-conversion of this steroid into $5 \alpha-\mathrm{DH}$ PROG. On the other hand, since $3 \alpha, 5 \alpha-\mathrm{TH}$ PROG is a well-known ligand of the $\mathrm{GABA}_{\mathrm{A}}$ receptor (Celotti et al., 1992; Melcangi et al., 1999b, 2001b), also a direct effect of this steroid via the interaction with this neurotransmitter receptor cannot be excluded. As previously mentioned, we have shown that $\mathrm{GABA}_{\mathrm{A}}$ receptor is expressed both in sciatic nerve and in Schwann cell cultures (Melcangi et al., 1999a). The situation is different in the case of PMP22, since only $3 \alpha, 5 \alpha-$ TH PROG is effective, and consequently a possible effect via the $\mathrm{GABA}_{\mathrm{A}}$ receptor might be taken in consideration. Recently, we have investigated these mechanisms using agonists and antagonists of $\mathrm{PR}$ and $\mathrm{GABA}_{\mathrm{A}}$ receptor. The data obtained have indicated that, at least in cultures of rat Schwann cells, Po is under the control of PR, while PMP22 depends on the $\mathrm{GABA}_{\mathrm{A}}$ receptor (Magnaghi et al., 2001). An effect on Po through the PR might be also supported by the identification of some progesterone-responsive elements (PRE) on the Po promoter (Magnaghi et al., 1999).

The finding that PROG and/or its derivatives are able to influence the expression of Po and PMP22 in the sciatic nerve of aged rats seems to be a peculiarity of these neuroactive steroids. In fact, $\mathrm{T}$ and its derivatives, DHT and
$3 \alpha$-diol, are totally unable to modify the synthesis of these two myelin proteins (Melcangi et al., 2000b). However, the situation is different when other in vivo (adult male rats) or in vitro (rat Schwann cells) experimental models are considered. For instance, in adult male rats, castration clearly decreases the Po mRNA levels in the sciatic nerve by about $40 \%$, and systemic administration of DHT is able to increase the levels of the messenger of this myelin protein (Magnaghi et al., 1999). Since, at variance to what happens with PR, Schwann cells seem not to express androgen receptor (AR) (Magnaghi et al., 1999), we have hypothesized that in our in vivo experiments, the gene expression of Po is stimulated by androgen-dependent mechanisms acting on Schwann cells in an indirect fashion. For instance, androgens might act through the neuronal component, which does contain AR (Magnaghi et al., 1999; Jordan et al., 2002). However, with similar treatments in cultures of rat Schwann cells, we have observed that DHT is able to increase the Po mRNA levels (Magnaghi et al., 1999). Consequently, we have tested the hypothesis that DHT might be able to activate Po gene expression by acting through a steroid receptor other than the AR. Since, as mentioned above, $5 \alpha-\mathrm{DH}$ PROG, a steroid that interacts with the PR, may activate Po gene expression (Melcangi et al., 1998a, 1999a), we have postulated that DHT might interact with the PR, and activate PRE. The data so far obtained indicate that, in a human neuroblastoma cell line (SK-N-MC) co-transfected with the $\mathrm{hPR}_{\mathrm{B}}$ and with a reporter plasmid containing a PRE, DHT is able to exert a transcriptional activity via the human PR (Magnaghi et al., 1999). Therefore, in addition to a neuronal mediated effect on Po gene expression, a co-operation between progestagens and androgens might be hypothesized.

Moreover, not only the gene expression of Po but also that of PMP22 seems to be modulated by $\mathrm{T}$ derivatives. We have observed that, in cultures of rat Schwann cells, $3 \alpha$-diol is able to significantly increase PMP22 mRNA levels (Magnaghi et al., 2001). This observation is interesting because of its similarity with the efficacy of $3 \alpha, 5 \alpha-\mathrm{TH}$ PROG on the same protein (Melcangi et al., 1999a). It has been proposed that $3 \alpha$-diol, which does not bind to the AR, might interact with $\mathrm{GABA}_{\mathrm{A}}$ receptor (Gee et al., 1988; Frye et al., 1996). Consequently, these observations further support the concept that the PMP22 mRNA levels are stimulated in Schwann cells via the $\mathrm{GABA}_{\mathrm{A}}$ receptor.

\section{Effects of neuroactive steroids on morphology of peripheral myelin}

On the basis of the effects exerted by neuroactive steroids on Po and PMP22 expression, we have evaluated whether pharmacological treatments with neuroactive steroids may prevent or counteract aging-associated morphological alterations of peripheral nerves. To this purpose, using the same in vivo experimental protocol mentioned in the previous section, we have analyzed the possible effect of PROG, 


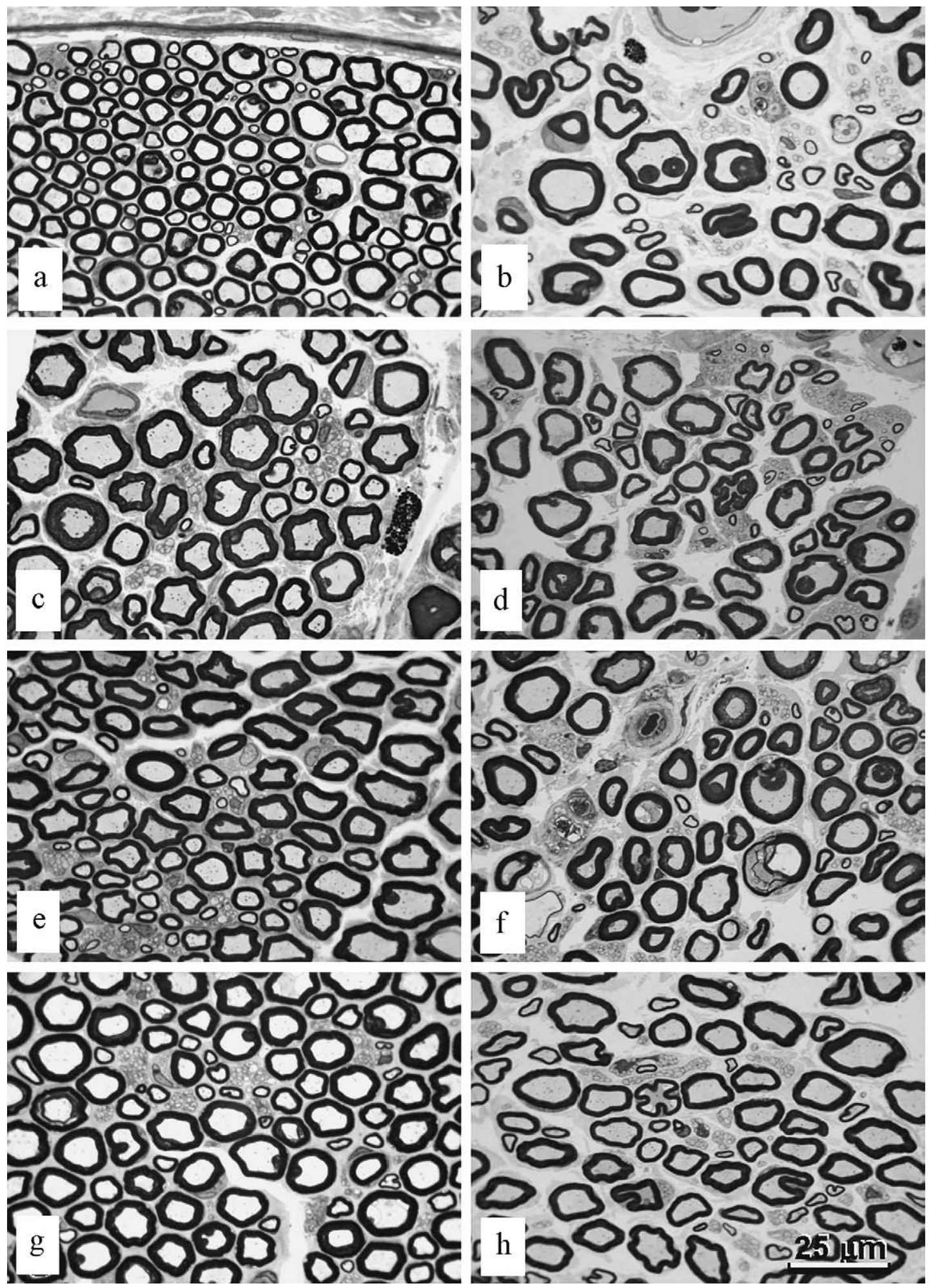

Fig. 4. Representative photomicrographs from the sciatic nerves of a adult rat (a) and of aged rats (22-24 months old) treated with vehicle only (b), progesterone (c), testosterone (d), dihydroprogesterone (e), dihydrotestosterone (f), tetrahydroprogesterone (g) or $3 \alpha$-diol (h). All figures are at the same magnification. Scale bar, $25 \mu \mathrm{m}$. 
$5 \alpha$-DH PROG and $3 \alpha, 5 \alpha-$ TH PROG on different morphological parameters of the myelin compartment of sciatic nerve of 22-24-month-old male rats. In a parallel experiment, the possible effects of $\mathrm{T}$ and its derivatives, DHT and $3 \alpha$-diol, have been also analyzed. Data obtained by treatment with PROG, $5 \alpha$-DH PROG or $3 \alpha, 5 \alpha-$ TH PROG indicate that these neuroactive steroids have clear effects on the number and shape of myelinated fibers as well as on the frequency of myelin abnormalities (Azcoitia et al., 2003). In particular, one of the most striking effects of PROG, $5 \alpha$-DH PROG and $3 \alpha, 5 \alpha-$ TH PROG is on myelinated fibers of small caliber $(<5 \mu \mathrm{m})$ with a significant increase in their number (Fig. 4). In contrast, the number of myelinated fibers of a size larger than $5 \mu \mathrm{m}$ is not significantly affected by the treatment with these neuroactive steroids. The increase in the number of small myelinated fibers after neuroactive steroid treatment is accompanied by a decrease of similar magnitude in the number of unmyelinated axons and, in particular, to large $(>3 \mu \mathrm{m})$ unmyelinated axons. Thus, sciatic nerves from rats treated with PROG or its derivatives show a significant decrease in the number of large unmyelinated axons compared to animals treated with vehicle $(1746 \pm 119,450 \pm 65,675 \pm 46$ and $560 \pm 66$ axons in rats treated with vehicle, PROG, $5 \alpha-\mathrm{DH}$ PROG and $3 \alpha, 5 \alpha$-TH PROG, respectively; $P<0.05$ ). Furthermore, the $g$ ratio of small myelinated fibers is significantly increased by PROG or its derivatives. This suggests that the increase in the number of myelinated fibers reflects an increased remyelination of small fibers in aged sciatic nerves.

Another marked effect of the treatments with PROG, $5 \alpha$-DH PROG and $3 \alpha, 5 \alpha-$ TH PROG is the reduction in the frequency of axons with myelin abnormalities. This effect is mainly due to a reduction in the frequency of axons with myelin infoldings, which decreases from $34.6 \pm 2.8 \%$ of the axons in animals treated with vehicle to $12.1 \pm 1.4$, $12.1 \pm 1.1$ and $20.9 \pm 2.8 \%$ in PROG-, $5 \alpha$-DH PROG- and $3 \alpha, 5 \alpha-$ TH PROG-treated animals, respectively. Moreover, PROG reduces the proportion of fibers with irregular shapes. As mentioned before, myelin abnormalities and irregular fiber profiles are typical markers of the aging process in peripheral nerves (Ceballos et al., 1999; Verdù et al., 2000). Therefore, our data indicate that PROG, $5 \alpha$-DH PROG and $3 \alpha, 5 \alpha$-TH PROG are able to reduce morphological changes associated with aging in the sciatic nerve.

The effects on the morphology of myelinated compartment of sciatic nerve of aged male rat so far mentioned seem to be a peculiarity of PROG and its derivatives. Neither T nor DHT or $3 \alpha$-diol is able to influence the morphological parameters analyzed in these experiments (Fig. 4) (Azcoitia et al., 2003). This situation is similar to the expression of myelin proteins in the sciatic nerve of aged male rat (Melcangi et al., 1998a,b, 2000b). Also in that case, while PROG and its derivatives are effective in increasing the low expression of Po and PMP22, T and its derivatives seem to be completely devoid of such effects.

\section{Conclusions}

The data summarized in the present review indicate that morphological and biochemical parameters of the myelin compartment of peripheral nerve are deeply influenced by the aging process. Interestingly, aging-associated alterations may be counteracted by the treatment with particular neuroactive steroids. Thus, neuroactive steroids are promising agents to prevent age-associated disorders of peripheral nerves. This new concept, when verified in other experimental models, might be extended to pathological situations such as demyelinating diseases (e.g., CMT1A, CMT1B, HNNP, DSS), peripheral nerve injury or diabetic neurophaty. Neuroactive steroids may thus represent useful therapeutic approaches to maintain peripheral nerve integrity.

\section{Acknowledgements}

The work described here has been supported by the Commission of the European Communities, specific RTD program "Quality of Life and Management of Living Resources", QLK6-CT-2000-00179, and HPMF-CT-200101144; Ministerio de Ciencia y Tecnología, Spain (SAF 2002-00652); FIRB 2001 (RBAU01kje4_001).

\section{References}

Adinolfi, A.M., Yamuy, J., Morales, F.R., Chase, M.H., 1991. Segmental demyelination in peripheral nerves of old cats. Neurobiol. Aging 12, $175-179$.

Azcoitia, I., Leonelli, E., Magnaghi, V., Veiga, S., Garcia-Segura, L.M., Melcangi, R.C., 2003. Progesterone and its derivatives dihydroprogesterone and tetrahydroprogesterone reduce myelin fiber morphological abnormalities and myelin fiber loss in the sciatic nerve of aged rats. Neurobiol. Aging 24, 853-860.

Baulieu, E.E., 1998. Neurosteroids: a novel function of the brain. Psychoneuroendocrinology 23, 963-987.

Berthold, C.-H., Nordborg, C., Hildebrand, C., Conradi, S., Sourander, P., Lugnegard, H., 1983. Sural nerve biopsies from workers with a history of chronic exposure to organic solvents and from normal control cases. Acta Neuropathol. (Berl.) 62, 73-86.

Braund, K.G., McGuire, J.A., Lincoln, C.E., 1982a. Age-related changes in peripheral nerves of the dog. I. A morphological and morphometric study of single-teased fibers. Vet. Pathol. 19, 365-378.

Braund, K.G., McGuire, J.A., Lincoln, C.E., 1982b. Age-related changes in peripheral nerves of the dog. II. A morphological and morphometric study of cross-sectioned nerve. Vet. Pathol. 19, 379-398.

Bronstein, J.M., 2000. Function of tetraspan proteins in the myelin sheath Curr. Opin. Neurobiol. 10, 552-557.

Burke, D., Skuse, N.F., Lethlean, A.K., 1974. Sensory conduction of the sural nerve in polyneuropathy. J. Neurol. Neurosurg. Psychiatry 37, 647-652.

Ceballos, D., Cuadras, J., Verdù, E., Navarro, X., 1999. Morphometric and ultrastructural changes with ageing in mouse peripheral nerve. $J$. Anat. 195, 563-576.

Celotti, F., Melcangi, R.C., Martini, L., 1992. The 5 $\alpha$-reductase in the brain: molecular aspects and relation to brain function. Front. Neuroendocrinol. 13, 163-215. 
Chan, J.R., Phillis II, L.J., Glaser, M., 1998. Glucocorticoids and progestins signal the initiation and enhance the rate of myelin formation. Proc. Natl. Acad. Sci. U.S.A. 95, 10459-10464.

Chan, J.R., Rodriguez-Waitkus, P.M., Ng, B.K., Liang, P., Glaser, M., 2000. Progesterone synthesized by Schwann cells during myelin formation regulates neuronal gene expression. Mol. Biol. Cell 11, 2283-2295.

Désarnaud, F., Do Thi, A.N., Brown, A.M., Lemke, G., Suter, U., Baulieu, E-E., Schumacher, M., 1998. Progesterone stimulates the activity of the promoters of peripheral myelin protein-22 and protein zero genes in Schwann cells. J. Neurochem. 71, 1765-1768.

Dyck, P.J., Lais, A.C., Karnes, J.C., Sparks, M., Hunder, H., Low, P.A., Windebank, A.J., 1981. Permanent axotomy, a model of axonal atrophy and secondary segmental demyelination and remyelination. Ann. Neurol. 9, 575-583.

Downie, A.W., Newell, D.J., 1961. Sensory nerve conduction in patients with diabetes mellitus and controls. Neurology 11, 876-882.

D’Urso, D., Brophy, P.J., Staugaitus, S.M., Gillespie, C.S., Frey, A.B., Stempak, J.G., Colman, D.R., 1990. Protein zero of peripheral nerve myelin: biosynthesis, membrane insertion, and evidence for homotypic interaction. Neuron 4, 449-460.

D’Urso, D., Eherhardt, P., Muller, H.W., 1999. Peripheral myelin protein 22 and protein zero: a novel association in peripheral nervous system myelin. J. Neurosci. 19, 3396-3403.

Eichberg, J., 2002. Myelin Po: new knowledge and new roles. Neurochem. Res. 27, 1331-1340.

Frye, C.A., Van Keuren, K.R., Erkine, M.S., 1996. Behavioral effects of 3alpha-androstanediol. I. Modulation of sexual receptivity and promotion of GABA-stimulated chloride flux. Behav. Brain Res. 79, 109-118.

Fruttiger, M., Montag, D., Schachner, M., Martini, R., 1995. Crucial role for the myelin-associated glycoprotein in the maintenance of axon-myelin integrity. Eur. J. Neurosci. 7, 511-515.

Gee, K.W., Bolger, M.B., Brinton, R.E., Coirini, H., McEwen, B.S., 1988. Steroid modulation of the chloride ionophore in rat brain: structure-activity requirements, regional dependence and mechanism of action. J. Pharmacol. Exp. Ther. 246, 803-812.

Giese, K.P., Martini, R., Lemke, G., Soriano, P., Schachner, M. 1992. Mouse Po gene disruption leads to hypomyelination, abnormal expression of recognition molecules, and degeneration of myelin and axons. Cell 71, 565-576.

Grover-Johnson, N., Spencer, P.S., 1981. Peripheral nerve abnormalities in aging rats. J. Neuropathol. Exp. Neurol. 40, 155-165.

Guennoun, R., Schumacher, M., Robert, F., Delespierre, B., Gouezou, M., Eychenne, B., Akwa, Y., Robel, P., Baulieu, E.E., 1997. Neurosteroids: expression of functional 3 $\beta$-hydroxysteroid dehydrogenase by rat sensory neurons and Schwann cells. J. Neurosci. 9, 2236-2247.

Johansson, C.S., Stenstrom, M., Hildebrand, C., 1996. Target influence on aging of myelinated sensory nerve fibers. Neurobiol. Aging 17, 61-66.

Jordan, C.L., Price Jr., R.H., Handa, R.J., 2002. Androgen receptor messenger RNA and protein in adult rat sciatic nerve: implications for site of androgen action. J. Neurosci. Res. 69, 509-518.

Jung-Testas, I., Schumacher, M., Robel, P., Baulieu, E-E., 1996. Demonstration of progesterone receptors in rat Schwann cells. J. Steroid Biochem. Mol. Biol. 58, 77-82.

Kanda, T., Tsukagoshi, H., Oda, M., Miyamoto, K., Tanabe, H., 1991. Morphological changes in unmyelinated nerve fibers in the sural nerve with age. Brain 114, 585-599.

Knox, C.A., Kokmen, E., Dyck, P.J., 1989. Morphometric alteration of rat myelinated fibers with aging. J. Neuropathol. Exp. Neurol. 48, 119-139.

Koella, W.P., 1979. Neurophysiology of aged animals. Biophysical and biochemical nervous system aspect of aging. In: Hoffmeister, F., Muller, C., Krause, H.P. (Eds.), Proceeding of the Bayer Symposium VII on Brain Function in Old Age, Springer, Berlin, pp. 394-407.

Koenig, H.L., Schumacher, M., Ferzaz, B., Do Thi, A.N., Ressouches, A., Guennoun, R., Jung-Testas, I., Robel, P., Akwa, Y., 1995. Progesterone synthesis and myelin formation by Schwann cells. Science 268, 15001503.

Koski, C.L., Max, S.R., 1980. Comparison of the protein composition of myelin of motor and sensory nerves. J. Neurochem. 34, 449-452.

Lascelles, R.G., Thomas, P.K., 1966. Changes due to age in internodal length in the sural nerve in man. J. Neurol. Neurosurg. Psychiatry 29, $40-44$.

Lemke, G., Axel, R., 1985. Isolation and sequence of a cDNA encoding the major structural protein of peripheral myelin. Cell 40, 501-508.

Lemke, G., 1986. Molecular biology of the major myelin genes. T.I.N.S. 9, 266-270.

Magnaghi, V., Cavarretta, I., Zucchi, I., Susani, L., Rupprecht, R., Hermann, B., Martini, L., Melcangi, R.C., 1999. Po gene expression is modulated by androgens in the sciatic nerve of adult male rats. Mol. Brain Res. 70, 36-44.

Magnaghi, V., Cavarretta, I., Galbiati, M., Martini, L., Melcangi, R.C., 2001. Neuroactive steroids and peripheral myelin proteins. Brain Res. Rev. 37, 360-371.

Martini, R., Zielasek, J., Toyka, K.V., Giese, K.P., Schachner, M., 1995. Protein zero (Po)-deficient mice show myelin degeneration in peripheral nerves characteristic of inherited human neuropathies. Nature Gen. 11, 281-286.

McCombe, P.A., Pollard, J.D., McLeod, J.G., 1987. Chronic inflammatory demyelinating polyradiculoneuropathy. Brain 110, 1617-1630.

Melcangi, R.C., Celotti, F., Ballabio, M., Poletti, A., Martini, L., 1990a. Testosterone metabolism in peripheral nerves: presence of the $5 \alpha$-reductase- $3 \alpha$-hydroxysteroid-dehydrogenase enzymatic system in the sciatic nerve of adult and aged rats. J. Steroid Biochem. 35, 145148.

Melcangi, R.C., Celotti, F., Ballabio, M., Castano, P., Massarelli, R., Poletti, A., Martini, L., 1990b. $5 \alpha$-Reductase activity in isolated and cultured neuronal and glial cells of the rat. Brain Res. 516, 229-236.

Melcangi, R.C., Celotti, F., Castano, P., Martini, L., 1992. Is the $5 \alpha$-reductase-3 $\alpha$-hydroxysteroid dehydrogenase complex associated with the myelin in the peripheral nervous system of young and old male rats? Endocrine Reg. 26, 119-125.

Melcangi, R.C., Celotti, F., Castano, P., Martini, L., 1993. Differential localization of the $5 \alpha$-reductase and the $3 \alpha$-hydroxysteroid dehydrogenase in neuronal and glial cultures. Endocrinology 132, 1252-1259.

Melcangi, R.C., Celotti, F., Martini, L., 1994. Progesterone 5 $\alpha$-reduction in neuronal and in different types of glial cell cultures: types 1 and 2 astrocytes and oligodendrocytes. Brain Res. 639, 202-206.

Melcangi, R.C., Magnaghi, V., Cavarretta, I., Martini, L., Piva, F., 1998a. Age-induced decrease of glycoprotein Po and myelin basic protein gene expression in the rat sciatic nerve. Repair by steroid derivatives. Neuroscience 85, 569-578.

Melcangi, R.C., Magnaghi, V., Cavarretta, I., Riva, M.A., Piva, F., Martini, L., 1998b. Effects of steroid hormones on gene expression of glial markers in the central and peripheral nervous system: variations induced by aging. Exp. Gerontol. 33, 827-836.

Melcangi, R.C., Magnaghi, V., Cavarretta, I., Zucchi, I., Bovolin, P., D’Urso, D., Martini, L., 1999a. Progesterone derivatives are able to influence peripheral myelin protein 22 and Po gene expression: possible mechanisms of action. J. Neurosci. Res. 56, 349-357.

Melcangi, R.C., Magnaghi, V., Martini, L., 1999b. Steroid metabolism and effects in central and peripheral glial cells. J. Neurobiol 40, 471-483.

Melcangi, R.C., Magnaghi, V., Galbiati, M., Ghelarducci, B., Sebastiani, L., Martini, L., 2000a. The action of steroid hormones on peripheral myelin proteins: a possible new tool for the rebuilding of myelin? J. Neurocytol. 29, 327-339.

Melcangi, R.C., Magnaghi, V., Martini, L., 2000b. Aging in peripheral nerves: regulation of myelin protein genes by steroid hormones. Prog. Neurobiol. 60, 291-308.

Melcangi, R.C., Magnaghi, V., Galbiati, M., Martini, L., 2001a. Glial cells a target for steroid hormones. Prog. Brain Res. 132, 31-40. 
Melcangi, R.C., Magnaghi, V., Galbiati, M., Martini, L., 2001b. Formation and effects of neuroactive steroids in the central and peripheral nervous system. Int. Rev. Neurobiol. 46, 145-176.

Mellon, S.H., Griffin, L.D., 2002. Neurosteroids: biochemistry and clinical significance. T.E.M. 13, 35-43.

Mendell, J.R., 1993. Chronic inflammatory demyelinating polyradiculoneuropathy. Annu. Rev. Med. 44, 211-219.

Morales, J.F.R., Boxer, P.A., Fung, S.J., Chase, M.H., 1987. Basic electrophysiological properties of spinal cord motoneurons during old age in the cat. J. Neurophysiol. 58, 180-194.

Naef, R., Suter, U., 1998. Many facets of the peripheral myelin protein PMP22 in myelination and disease. Microsc. Res. Tech. 41, 359-371.

Nelles, E., Butzler, C., Jung, D., Temme, A., Gabriel, H.D., Dahl, U., Traub, O., Stumpel, F., Jungermann, K., Zielasek, J., Toyka, K.V., Dermietzel, R., Willecke, K., 1996. Defective propagation of signals generated by sympathetic nerve stimulation in the liver of connexin 32-deficient mice. Proc. Natl. Acad. Sci. U.S.A. 93, 9565-9570.

Norris, A.H., Shock, N.W., Wagman, I.H., 1953. Age changes in maximum conduction velocity of motor fibers of human ulnar nerves. J. Appl. Physiol. 5, 589-593.

Parhad, I.M., Scott, J.N., Cellars, L.A., Bains, J.S., Krekoski, C.A., Clark, A.W., 1995. Axonal atrophy in aging is associated with a decline in neurofilament gene expression. J. Neurosci Res. 41, 355-366.

Quarles, R.H., 1997. Glycoproteins of myelin sheaths. J. Mol. Neurosci. $8,1-12$.

Retzlaff, E., Fontaine, J., 1965. Functional and structural changes in motor neurons with age. In: Welford, A.T., Birren, J.E. (Eds.), Behavior, Aging and the Nervous System. Thomas, Springfield, pp. 340-352.

Rivner, M.H., Swift, T.R., Malik, K., Rivner, M.H., Swift, T.R., Malik, K., 2001. Influence of age and height on nerve conduction. Muscle Nerve 24, 1134-1141.

Sakamoto, Y., Kitamura, K., Yosjimura, K., Nishijima, T., Uyemura, K., 1987. Complete amino acid sequence of Po protein from bovine peripheral nerve myelin. J. Biol. Chem. 262, 4208-4214.

Sato, A., Sato, Y., Suzuki, H., 1985. Aging effects on conduction velocities of myelinated and unmyelinated fibers of peripheral nerves. Neuroscience Lett. 53, 15-20.

Scherer, S.S., Xu, Y.T., Nelles, E., Fischbeck, K., Willecke, K., Bone, L.J., 1998. Connexin 32-null develop demyelinating peripheral neuropathy. GLIA 24, 8-20.

Schumacher, M., Guennoun, R., Mercier, G., Désarnaud, F., Lacor, P., Bénavides, J., Ferzaz, B., Robert, F., Baulieu, E.E., 2001. Progesterone synthesis and myelin formation in peripheral nerves. Brain Res. Rev. 37, 343-359.

Shy, M.E., Arroyo, E., Sladky, J., Menichella, D., Jiang, H., Xu, W., Kamholz, J., Sherer, S.S., 1997. Heterozygous Po knockout mice develop a peripheral neuropathy that resembles chronic inflammatory demyelinating polyneuropathy (CIDP). J. Neuropat. Exp. Neurol. 56, 811-821.

Smith, D.O., Rosenheimer, J.L., 1984. Factors governing speed of action potential conduction and neuromuscular transmission in aged rats. Exp. Neurol. 83, 358-366.

Snipes, G.J., Suter, U., 1995. Molecular anatomy and genetics of myelin proteins in the peripheral nervous system. J. Anat. 186, 483494.

Spencer, P.S., Thomas, P.K., 1970. The examination of isolated nerve fibers by light and electron microscopy with observations on demyelination proximal to neuromas. Acta Neuropathol. (Berl.) 16, 177-186.

Suter, U., Snipes, G.J., 1995. Biology and genetics of hereditary motor and sensory neurophaties. Annu. Rev. Neurosci. 18, 45-75.

Swallow, J.S., Griffiths, I.R., 1977. Age related changes in the motor nerve conduction velocity in dogs. Res. Vet. Sci. 23, 29-32.

Thomas, P.K., King, R.H.M., Sharma, A.K., 1980. Changes with age in the peripheral nerves of the rat. Acta Neuropathol. (Berl.) 52, 417-428.

Uchida, Y., Tomonaga, M., Nomura, K., 1986. Age-related changes of myelin proteins in the rat peripheral nervous system. J. Neurochem. 46, 1376-1381.

Verdù, E., Buti', M., Navarro, X., 1996. Functional changes of the peripheral nervous system with aging in the mouse. Neurobiol. Aging 17, 73-77.

Verdù, E., Cevallos, D., Vilches, J.J., Navarro, X., 2000. Influence of aging on peripheral nerve function and regeneration. J. Peripher. Nerv. Syst. 5, 191-208.

Wagman, I.H., Lesse, H., 1952. Maximum conduction velocities of motor fibers of ulnar nerve in human subjects of various ages and sizes. J. Neurophysiol. 15, 235-244.

Wayner, M.J., Emmers, R., 1958. Spinal synaptic delay in young and aged rats. Am. J. Physiol. 194, 403-405.

Welcher, A.A., Suter, U., De Leon, M., Snipes, G.J., Shooter, E., 1991. A myelin protein is encoded by the homologue of a growth arrest-specific gene. Proc. Natl. Acad. Sci. U.S.A. 88, 7195-7199.

Zielasek, J., Martini, R., Toyka, K.V., 1996. Functional abnormalities in Po-deficient mice resemble human hereditary neuropathies linked to Po gene mutations. Muscle Nerve 19, 946-952. 